\section{Pharmacological and non-phar- macological treatment options for depression and depressive symptoms in hemodialysis patients}

\author{
Stefania S. Grigoriou, Christina \\ Karatzaferi, Giorgos K. Sakkas \\ Department of Physical Education and \\ Sport Science, University of Thessaly, \\ Trikala; Institute of Research and \\ Technology Thessaly, Centre for Research \\ and Technology-Hellas, Trikala, Greece
}

\begin{abstract}
Depression is a mental disorder with a high prevalence among patients with end stage renal disease (ESRD). It is reported that depression afflicts approximately $20-30 \%$ of this patient population, being associated, amongst other, with high mortality rate, low adherence to medication and low perceived quality of life. There is a variety of medications known to be effective for the treatment of depression but due to poor adherence to treatment as well as due to the high need for medications addressing other ESRD comorbidities, depression often remains untreated. According to the literature, depression is under-diagnosed and undertreated in the majority of the patients with chronic kidney disease. In the current review the main pharmacological and non-pharmacological approaches and research outcomes for the management of depressive symptoms in hemodialysis patients are discussed.
\end{abstract}

\section{Introduction}

End stage renal disease (ESRD) treated with hemodialysis (HD), is often associated with several comorbidities like hypertension, heart diseases, musculoskeletal problems and diabetes mellitus. ${ }^{1}$ Patients receiving HD therapy exhibit low levels of perceived quality of life, usually accompanied by significant emotional distress characteristics such as symptoms of depression and anxiety. ${ }^{2}$ According to the literature, depression is the most common mental disorder in HD patients affecting approximately the $20 \%$ of this specific patients group and reported to be the second only to hypertension in frequency as a comorbid diagnosis.3-5 The last decade, nephrologists have looked systematically for signs of depression since depression is recognized as an important factor which among others, influences the overall health status and survival of the patient. 6

The aim of this review is to describe and cover in critical fashion the various treatment options available for the management of depression in patients receiving HD therapy and whether those regimes are effective in improving patients' mental health.

\section{Depression in hemodialysis patients}

\section{Definition}

According to the $4^{\text {th }}$ edition of the Diagnostic and Statistical Manual of Mental Disorders (DMS-IV), depression is defined by having a loss of pleasure or interest for at least a two week period, accompanied by 5 or more psychological, somatic and behavioral symptoms. It is noteworthy that the World Health Organization ranks depression as the leading cause of disability and the fourth leading contributor to the global burden of disease in 2000 worldwide. 7 The same organization's projections indicate that depression will be the highest ranked cause of disease burden in developed countries by the year 2020 . Sadness, emotional inhibitions, fatigue, sleep disturbances, loss of concentration, intense guilt, and thoughts of suicide or death are some of the symptoms associated with major depression while thoughts of suicide and death are particular symptoms that are of great concern for the general public. 8,9

\section{Epidemiology}

According to the World Health Organization (WHO) depression is considered to be the second most common condition in the general population with the reported prevalence of lifetime depression to be around $16 \%{ }^{10}$ Research findings suggest that the prevalence of depression in the general population is about 12 $20 \%, 11$ with women reporting higher scores compared to men. In a large WHO study with 245,404 participants from 60 countries from all regions of the world, the prevalence of depression based on ICD-10 criteria was $3.2 \%$, while interestingly, in patients with one or more chronic disease the prevalence of depression climbed between $9.3 \%$ and $23.0 \% .12$ In a very recent cross-national study from 18 countries the average lifetime and 12 -month prevalence of depression were $14.6 \%$ and $5.5 \%$ respectively in the high-income counties and $11.1 \%$ and $5.9 \%$ respectively in the low- to middle-income countries. 13 Depression is one of the most common psychiatric abnormalities in patients with ESRD,14,15 affecting approximately 20$30 \%$ of the patients, ${ }^{16-18}$ with some studies reporting even higher percentages. 19

\section{Etiology of depression in hemodialy- sis patients}

Causes of depression are linked also to the
Correspondence: Giorgos K. Sakkas, Department of Kinesiology, Centre for Research and Technology Hellas, LIVE Lab, Trikala, Thessaly, Greece.

Tel.: +30.2431 .500 .911 - Fax: +30.2431 .063 .190 .

E-mail: gsakkas@med.uth.gr

Key words: Dialysis; quality of life; survival; exercise; alternative medicine.

Contributions: SSG, literature survey, writing the review, corrections; CK, GKS, writing the review, editing the review, corrections.

Conflict of interest: the authors declare no potential conflict of interest.

Received for publication: 3 July 2014.

Revision received: 1 December 2014.

Accepted for publication: 1 December 2014.

This work is licensed under a Creative Commons Attribution NonCommercial 3.0 License (CC BYNC 3.0).

CC Copyright S.S. Grigoriou et al., 2015

Licensee PAGEPress, Italy

Health Psychology Research 2015; 3:1811

doi:10.4081/hpr.2015.1811

dialysis treatment per se, which requires from a patient to stay attached to the dialysis machine for approximately 4 hours, 3 times a week, a necessity that contributes significantly to a patient's low quality of life and restricts independent living. ${ }^{20}$ It is noteworthy that health care providers frequently fail to identify and/or treat depression in HD patients (70\%) despite the high prevalence of the disease.21 In addition, factors such as medication side effects and dietary restrictions may further contribute to the impaired levels of perceived quality of life and the emotional distress experience by the HD population, leading to more severe symptoms. ${ }^{22,23}$ Other factors that could be blamed for the high prevalence of depression in HD patients are social in nature such as work loss, alterations in one's family role, experience of multiple losses, medication adherence, $14,23-25$ low monthly income, years on dialysis and unemployment. 26,27 Further, there is some evidence suggesting that depression in HD patients could be the result of factors such as a decline in cognitive skills and sexual function, ${ }^{28,29}$ as well as low education levels. ${ }^{30}$ It's important to recognize that HD patients face many additional challenges which increase the possibility of developing depression or anxiety or other mental conditions. Patients experience major changes in their lifestyle. On the one hand they have very limited, if any, alternative options to the proposed or available treatment of their end-stage renal disease state 
(which requires strict compliance to their dialysis and medicinal regime). This includes having to adjust to a rigorous dietary prescription and a very limited fluid intake. On the other hand, it also becomes a challenge for many HD patients to maintain meaningful life roles regarding employment, family life, and friendships. HD patients have not only to cope with the anger, fear, anxiety, frustration, and sadness of having a serious chronic illness but have also to accept a curtailment of their independence. Finally they have to confront their own mortality and the likelihood of a shortened life span. ${ }^{31}$ Depression in HD patients is characterized by both cognitive and somatic features. The problem is that somatic features of depression such as anorexia, sleep disturbances, fatigue and gastrointestinal disorders, are also common symptoms of uremia. 32,33 For this reason there is added difficulty in diagnosing depression in HD patients, i.e. the identifying a mental illness against the backdrop of the physical illness. ${ }^{14,34-36}$ It is also challenging to distinguish the non-uremia induced depressive symptoms from known uremic-induced symptoms such as irritability, cognitive dysfunction, or mild symptoms of encephalopathy or from drug effects or symptoms of inadequate dialysis. It is noteworthy that depression as a mental disorder when it coexists with another psychiatric or medical illness, may render depression relatively to treatment. $14,35-38$

\section{Research questions and search strategy}

The primary questions of this review were: what are the main pharmacological and nonpharmacological approaches and research outcomes for the reduction of symptoms of depression in HD patients? The following databases were searched: MEDLINE, PUBMED, PsycINFO and SCOPUS. The keywords used were: hemodialysis, end stage renal diseases, renal failure, depression, depressive symptoms, pharmacological, non pharmacological, alternative medicine, exercise, medication, drugs, quality of life. We organized our evaluation of the literature in the following sections: measurement of depression, treatment options including pharmacological management, 1 st generation antidepressants, 2nd generation antidepressants, non-pharmacological management, including psychotherapeutic approach, alternative therapeutic approaches and exercise. We strived to gather information pertaining to ESRD-HD patients but when not available we report on studies within the chronic renal disease spectrum.

\section{Measurement of depression}

The Beck Depression Inventory (BDI) is one of the most established instruments used to measure the presence and severity of depression. It is a 21-question inventory developed to measure the degree and severity of the depression's symptoms..$^{39}$ A score of 14-16 or more has been reported to be an accurate measure for the diagnosis of depression in the HD population and has been successfully used, in its original or revised forms. ${ }^{40}$ Also, one of the most frequently used personality tests is the Minnesota Multiphasic Personality Inventory (MMPI). 40 It's a self-report instrument and contains 566 positive statements dealing with thoughts, feelings, attitudes, physical symptoms and quality of life. ${ }^{41,42}$

Many times instruments assessing aspects of quality of life (QoL) are also used for assessing mental health. The most common questionnaire found in the literature is the $S F-36$ questionnaire - a self-administered instrument containing 36 items, ${ }^{43}$ which assesses health related QoL on eight multi-item dimensions, including vitality and mental health.

In clinical practice, the Nine-Question Patient Health Questionnaire (PHQ-9), ${ }^{44}$ a selfreport instrument, is often used to detect five common mental disorders in primary care: depression, anxiety, alcohol abuse, somatoform disorder, and eating disorder. Another instrument used for measuring depression is the Hamilton Rating Scale for Depression. 45 The questionnaire lists 21-items and rates the severity of symptoms observed in depression such as low mood, insomnia, agitation, anxiety and weight loss.46 Moreover, an appropriate tool for assessing depressive symptomatology in the general population is the Center for Epidemiologic Studies Depression Scale (CED). ${ }^{47}$ A self-report questionnaire, that contains 20 items and asks caregivers to rate how often over the past week they experienced symptoms associated with depression, such as restless sleep, poor appetite, and feeling lonely. Additionally, the Zung Self-Rating Depression Scale contains 20 items, 48 ten positively worded and ten negatively worded questions, assessing the level of depression or depressive symptoms. 49,50

\section{Treatment options}

According to the literature, depression is not only under-diagnosed, but it is also undertreated in patients with chronic kidney disease. ${ }^{51}$ In the following text, the main pharmacological and non-pharmacological approaches and research outcomes for the reduction of depression symptoms in HD patients are discussed.

\section{Pharmacological management}

Multiple classes of medications are available for treatment of depression in the patient with chronic diseases. Despite the availability of high-tech brain imaging systems, health care providers have to prescribe antidepressants using their clinical judgment and other factors such as effectiveness, toxicity, expense, and ease of administration. Most studies support that low doses of antidepressant medications can have therapeutic results in patients maintained on dialysis (Table 1).52-67 There are 2 classes of medication with proven benefits for the depressed patient divided in $1^{\text {st }}$ and $2^{\text {nd }}$ generation.

\section{First generation antidepressants}

Desipramine and tricyclic antidepressants (TCAs) are used orally for treating major depressive disorder. TCAs have been used clinically to treat patients with major depressive illness since the early 1960s. In a small study, the use of TCAs showed a positive effect in HD patients' levels of depression while in a study by Lee and colleagues (2004), 54 antidepressant treatment decreased the serum level of interleukin-betal and increased the serum level of interleukin-6 improving patients' depression symptoms' severity with parallel improvements in various immunological and nutritional indices. 54 Other pharmacological options for the treatment of depression include monoamine oxidase inhibitors (MAOI) and reverse inhibitors of MA0.28,68,69

\section{Second generation antidepressants}

The second generation of antidepressants consists of a category called selective serotonine reuptake inhibitors (SSRIs) including venlafaxine, mirtazapine, bupropion, nefazodone, duloxetine, fluoxetine and fluvoxamine. These act on the central nervous system through their effects on neurotransmitters such as serotonin, norepinephrine, or dopamine. Koo and colleagues (2005) examined the effect of antidepressant treatment in HD patients treated with paroxetine for 8 weeks and found a significant improvement in depressive symptoms.55 In one study the safety of fluoxetine in patients with kidney disease was assessed. Specifically nine depressive patients with normal renal failure and seven HD patients were given fluoxetine $20 \mathrm{mg} / \mathrm{d}$ in an 8 week study. Depression was assessed by HAMD-17, BDI, Montgomery Asberg Depression Rating Scale, Brief Symptom Inventory, Global Well-being Scale, and the Electronic Visual Analog Scale before, during 
and at the conclusion of the 8-week study period. Five of six patients in both the ESRD group and the normal renal function group experienced significant decreases in their overall depression scores with an approximately $25 \%$ reduction in the HAMD-17 score. 57

In an another study, the authors found that 8 weeks of SSRIs treatment was enough to improve depression with a concomitant improvement in quality of patients' life. $56 \mathrm{~A}$ year later Kalender et al., (2007) treated HD, peritoneal dialysis and pre-dialysis patients with citalopram, and found very similar results. 70

\section{Non-pharmacological management}

There is a wide spectrum of non-pharmacological and psychotherapeutic techniques for the management of depression in HD patients. ${ }^{71}$ In the text below the main nonpharmacological treatment options are discussed exploring in depth their effectiveness and potential for use in this group of patients.

\section{Psychotherapeutic approach}

Cognitive Behavioral Therapy (CBT) can be characterized as a comprehensive system of psychotherapy which combines both behavior theory and cognitive learning theory and implements strategies to change chronic patients' way of thinking and attitudes. ${ }^{72,73}$ Current evidence shows that depression is an important target of psychological assessment in HD patients, further supported by evidence showing a significant improvement in the mood of these patients. ${ }^{5}$ Consistent with previous studies, HD patients who had the opportunity to engage in cognitive behavioral therapy and to share their feelings concerning their disease, exhibit lower levels of depression and stress. ${ }^{74}$ Similar improvements were presented in the study by Lii et al., where group therapy successfully reduced patient's depression symptoms.59 Furthermore, support from the family and the immediate social circle can decrease depression symptoms by improving patients' self-esteem.75

Recently, a structured psychological intervention was successfully applied in ESRD patients resulting in significant improvements in emotional distress indices such as depression, anxiety and worries thoughts leading to a parallel improvement of patient's QoL score.60

Relaxation and imagery techniques have been successfully applied in patients with chronic disease in order to reduce depression symptoms. ${ }^{61}$ However, it seems that those techniques may not be as effective in HD patients, despite the fact that the patient's adherence to interventions and their self-satisfaction was significantly improved. ${ }^{76}$ Tsay and Hung (2004) examined the effects of an empowerment intervention program in $\mathrm{HD}$ patients indicating a significant improvement both in depression symptoms as well as in selfcare and self-efficacy of the participants. ${ }^{62}$ Even though these techniques look very promising for the amelioration or therapy of depres-

Table 1. Overview of depression treatment in hemodialysis patients.

\begin{tabular}{|c|c|c|c|c|c|}
\hline Reference & Intervention & Diagnosis & Period & Methodology & Outcomes \\
\hline Wuerth et al. ${ }^{2}$ & $\begin{array}{l}7 \text { (patients) sertraline, } \\
2 \text { bupropion, } \\
2 \text { nefazodone }\end{array}$ & Clinical depression & 12 weeks & $\begin{array}{l}\text { BDI, HAMD, } \\
\text { psychiatric interview }\end{array}$ & $\begin{array}{c}\text { Improvement } \\
\text { in depressive symptoms }\end{array}$ \\
\hline Kennedy et al.53 & $\begin{array}{l}\text { Antidepressant } \\
\text { therapy (not stated) }\end{array}$ & Major depression & 7 weeks & $\begin{array}{l}\text { BDI, HAMD, MMSE, } \\
\text { dardized antidepressar } \\
\text { side effect checklist }\end{array}$ & $\begin{array}{c}\text { Significant recovery } \\
\text { ant, in five patients, improvement in one, } \\
\text { and discontinuation of therapy } \\
\text { in the remaining two }\end{array}$ \\
\hline Lee et al. 54 & $20 \mathrm{mg}$ of fluoxetine & Depressed mood & 8 weeks & HAMD & $>50 \%$ reduction in the score of the HAND \\
\hline Koo et al. 55 & Paroxetine $10 \mathrm{mg} /$ day & Not specified & 8 weeks & BDI & Changes in depression and nutritional status \\
\hline Turk et al. 56 & Sertralin HCl, 50 mg/day & $\begin{array}{l}\text { Patients who had BDI } \\
\text { score } \geq 15 \text { were diagnosed } \\
\text { as depressed }\end{array}$ & 8 weeks & BDI & Improvement in QOL \\
\hline Levy et al. ${ }^{57}$ & Fluoxetine $20 \mathrm{mg} /$ day & Depression & 8 weeks & DSM-III-R, HAMD-17 & Improvement in depressive symptoms \\
\hline Koo et al. 55 & Paroxetine $10 \mathrm{mg} /$ day & Depressive symptoms & 8 weeks & BDI, HAMD & $\begin{array}{l}\text { Improvement in depressive symptoms } \\
\text { and nutritional status }\end{array}$ \\
\hline Turk et al.56 & Sertralin $\mathrm{HCl}, 50 \mathrm{mg}$ /day & Depression & 8 weeks & BDI & Improvement in QoL \\
\hline Duarte et al. 58 & $\begin{array}{l}\text { Cognitive-behavioral } \\
\text { therapy }\end{array}$ & Major depression & 3 months & BDI, SF-36 & $\begin{array}{l}\text { Improvement in depressive } \\
\text { symptoms }\end{array}$ \\
\hline Lii et al. ${ }^{59}$ & Psychosocial intervention & depression & 2-months & BDI, SF-36 & $\begin{array}{l}\text { Depression symptoms and QoL } \\
\text { improved significantly }\end{array}$ \\
\hline Rocha et al..$^{60}$ & $\begin{array}{l}\text { No regular } \\
\text { psychological } \\
\text { intervention }\end{array}$ & Depressive symptoms & No details & HADS & $\begin{array}{l}\text { A significant reduction of } \\
\text { depression symptoms }\end{array}$ \\
\hline Jorm et al. .1 & Relaxation techniques & Depressive symptoms & No details & CCDAN & $\begin{array}{l}\text { Effective at reducing self-rated } \\
\text { depressive symptoms }\end{array}$ \\
\hline Tsay et al.62 & Empowerment program & Depression & 6 weeks & BDI & Improvement in depressive symptoms \\
\hline Cho et al. .3 & Acupressure with massage & Depression & 4 weeks & BDI & Improvement in depressive symptoms \\
\hline Kim et al. 64 & Music therapy & Depression & No details & No details & Improvement in depressive symptoms \\
\hline Babyak et al. .5 & $\begin{array}{l}\text { Aerobic exercise } \\
\text { (3 times per week) } \\
\& \text { sertraline therapy }\end{array}$ & $\begin{array}{l}\text { Major depressive } \\
\text { disorder }\end{array}$ & 6 months & HRSD & Improvement in depressive symptoms \\
\hline Kouidi et al. 66 & Intradialytic exercise & Emotional distress & 1 year & BDI, HADS & Exercise training reduced emotional distress \\
\hline Jung et al. 67 & $\begin{array}{l}\text { Aerobic and resistance } \\
\text { exercise }\end{array}$ & - & eeks - 12 months & SF-36 & $\begin{array}{l}\text { Aerobic and resistance exercise improved } \\
\text { depression, and health-related QoL }\end{array}$ \\
\hline
\end{tabular}

BDI, Beck depression inventory; MMSE, mini mental state exam; MH (SF36), mental health (short form health survey 36); HADS, hospital anxiety and depression scale; RAND 36, RAND 36-item health survey; CCDAN, the cochrane collaboration depression, anxiety and neurosis review group; HRSD, Hamilton rating scale for depression; QoL, quality of life. 
sion, more research is needed on their effectiveness in dialysis and other chronic disease patients.

\section{Alternative therapeutic approaches}

Alternative therapeutic approaches have always been attractive to chronically ill mental patients since they satisfy their urge for trying and using new ways for relieving their mental and emotional symptoms and at the same time they allow patients to detach themselves from their current medication and possible invasive methods of therapy. For instance, the effectiveness of acupressure with massage in ameliorating fatigue and depression in HD patients was examined by Cho and Tsay (2004). Interestingly, the acupressure group reported significantly greater improvements on both fatigue and depression symptoms than the respective group of patients who received the regular unit care. ${ }^{63}$ Melody and rhythm are two special ways to express feelings and emotions and could be considered as an alternative way of depression treatment. Kim and colleagues (2006) showed that patients treated with music therapy reported a lower score in depression levels compared to the control group who received no therapy. 64 The positive impact of music on emotional distress indices was confirmed in a very recent study by Lin $e t$ al., where the authors observed that the patients who listened to music during the dialysis sessions exhibited significant reductions in perceived stressors and adverse reactions, a fact that led the authors to conclude that music could be beneficial for promoting wellbeing in HD patients. 77

\section{Exercise training}

Low levels of physical activity have been associated with depression. ${ }^{78}$ Aerobic and resistance exercise have beneficial effects on dialysis patients' well-being. Specifically aerobic exercises improve not only physical functioning but also improved nutritional status, hematological indices, inflammatory cytokines, depression, and health-related QoL.15 For example, depressive HD patients who participated in a moderate aerobic exercise program improved their depressive symptoms and had lower relapse rates compared with patients that received sertraline. ${ }^{65,79}$ Kouidi et al., (2010) examining the effect of exercise training on Heart Rate Variability and depression in HD patients, reported a beneficial effect of an intra-dialytic exercise program on both mental and cardiac autonomic disturbances. ${ }^{66}$ Also the same researchers showed a relationship between depression and cardiac autonomic dysfunction.66 Moreover, in HD patients with significant motor symptoms (restless legs syndrome) and sleep problems (sleep apneas and periodic leg movements), which also affect mental health, exercise has been shown to improve symptomatology, reduce depressive symptoms, and improve QoL.80,81

Based on such and other beneficial results of exercise, many research groups suggest that exercise should be a mandatory not an optional intervention in HD patients because of its beneficial effects on the overall health of this population. 15,67

\section{Conclusions}

Hemodialysis patients suffer from many physical and mental conditions. Depression is the most common psychological disorder encountered in 20-30\% of HD patients. While hemodialysis is indisputably a life-sustaining treatment for end-stage renal patients it also has an adverse impact on the mental status of these patients.

Depression in HD patients results in poor QoL and higher mortality risk and therefore the need for its successful treatment should receive special attention from nephrologists and other specialists involved in renal patients' care. Many medications have been shown to be effective for the treatment of depression but due to patient's poor adherence in treatment as well as due to the high need for medication related to the other comorbidities, depression often remains untreated. To cope with depressive symptoms and improve overall QoL, it becomes imperative to implement a multidimensional approach that includes different intervention strategies.

Treatment of depression should be administered by a team of professionals (psychologists, nurses, physicians, social workers and others) applying different regimes and strategies to provide a better care for the hemodialysis population. It should be noted that the dialysis environment could be an ideal place to observe mood changes, behavior and mental status, however, dialysis units do not usually provide the appropriate privacy for discreet discussions between the patients and health care providers.

In conclusion, depression is a disease that needs to be treated the earliest possible in the life of a hemodialysis patient since it can affect his or her QoL and overall survival. More research is needed to further explore the effectiveness and safety of trusted or new methods for the treatment of depression and depressive symptoms in HD patients.

\section{References}

1. Miskulin DC, Athienites NV, Yan G, et al. Comorbidity assessment using the index of Coexistent Diseases in a multicenter clinical trial. Kidney Int 2001;60:1498-510.

2. Finkelstein FO, Wuerth D, Finkelstein SH. Health related quality of life and the CKD patient: challenges for the nephrology community. Kidney Int 2009;76:946-52.

3. Hedayati SS, Finkelstein FO. Epidemiology, diagnosis, and management of depression in patients with CKD. Am J Kidney Dis 2009;54:741-52.

4. System URD. USRDS 2004 annual data report: atlas of end-stage renal disease in the United States. Bethesda: National Institutes of Health, National Institute of Diabetes and Digestive and Kidney Diseases; 2004.

5. U.S. Department Of Health And Human Services. Physical activity and Health: a report of the surgeon general. 1999. Available from: http://www.cdc.gov/nccdphp/sgr/index.htm

6. Rosenthal Asher D, Ver Halen N, Cukor D. Depression and nonadherence predict mortality in hemodialysis treated endstage renal disease patients. Hemodial Int 2012;16:387-93.

7. WHO. Mental health: depression. 2012. Available from: http://www.who.int/mental_health/management/depression/en/ind ex.html.

8. American Psychiatric Association. Diagnostic criteria from DSM-IV-TR. Washington, DC: American Psychiatric Association; 2000. p 370.

9. American Psychiatric Association. Diagnostic and statistical manual of mental disorders. 4th ed.,Washington, DC: American Psychiatric Association; 1994.

10. Kessler RC, Berglund P, Demler 0, et al. The epidemiology of major depressive disorder: results from the national comorbidity survey replication (NCS-R). JAMA 2003;289:3095-105.

11. Breslau K. Ready for his close-up. Newsweek 2004;144:12.

12. Moussavi S, Chatterji S, Verdes E, et al. Depression, chronic diseases, and decrements in health: results from the World Health Surveys. Lancet 2007;370:851-8.

13. Bromet E, Andrade LH, Hwang I, et al. Cross-national epidemiology of DSM-IV major depressive episode. BMC Med 2011; 9:90.

14. Kimmel PL. Psychosocial factors in dialysis patients. Kidney Int 2001;59:1599-613.

15. Mitrou GI, Grigoriou SS, Konstantopoulou E, et al. Exercise training and depression in ESRD: a review. Semin Dial 2013;26:604-13

16. Drayer RA, Piraino B, Reynolds CF 3rd, et al. Characteristics of depression in hemodialysis patients: symptoms, quality of life and mortality risk. Gen Hosp Psychiatry 2006;28:306-12. 
17. Drayer RA, Mulsant BH, Lenze EJ, et al. Somatic symptoms of depression in elderly patients with medical comorbidities. Int $\mathrm{J}$ Geriatr Psychiatry 2005;20:973-82.

18. Finkelstein FO, Finkelstein SH. Depression in chronic dialysis patients: assessment and treatment. Nephrol Dial Transplant 2000;15:1911-3.

19. Garcia-Lizana F, Munoz-Mayorga I. Telemedicine for depression: a systematic review. Perspect Psychiatr Care 2010;46:119-26.

20. Theofilou P, Panagiotaki E. Factors affecting quality of life in patients with endstage renal disease. Nursing 2010;49:17481.

21. Johnson S, Dwyer A. Patient perceived barriers to treatment of depression and anxiety in hemodialysis patients. Clin Nephrol 2008;69:201-6.

22. Kimmel PL. Depression in patients with chronic renal disease. What we know and what we need to know. J Psychosom Res 2002;53:951-6.

23. Chilcot, J., Wellsted D, Da Silva-Gane M, Farrington K. Depression on dialysis. Nephron Clin Pract 2008;108:256-64.

24. Chilcot J, Wellsted D, Farrington K. Screening for depression while patients dialyse: an evaluation. Nephrol Dial Transplant 2008;23:2653-9.

25. Theofilou P. Medication adherence in Greek hemodialysis patients: the contribution of depression and health cognitions. Int J Behav Med 2013;20:311-8.

26. Rai M, Rustagi T, Rustagi S, Kohli R. Depression, insomnia and sleep apnea in patients on maintenance hemodialysis. Indian J Nephrol 2011;21:223-9.

27. Araujo SM, de Bruin VM, Daher Ede F, et al. Risk factors for depressive symptoms in a large population on chronic hemodialysis. Int Urol Nephrol 2012;44:1229-35.

28. Cohen SD, Norris L, Acquaviva K, et al. Screening, diagnosis, and treatment of depression in patients with end-stage renal disease. Clin J Am Soc Nephrol 2007;2:1332-42.

29. Theofilou PA. Sexual functioning in chronic kidney disease: the association with depression and anxiety. Hemodial Int 2012;16:76-81.

30. Araujo SM, Mourão TC, Oliveira JL, et al. Antimicrobial resistance of uropathogens in women with acute uncomplicated cystitis from primary care settings. Int Urol Nephrol 2011;43:461-6.

31. Feroze U, Martin D, Reina-Patton A, et al. Mental health, depression, and anxiety in patients on maintenance dialysis. Iran J Kidney Dis 2010;4:173-80.

32. Hedayati SS, Finkelstein FO. Epidemiology, diagnosis, and management of depression in patients with CKD. Am J
Kidney Dis 2009;54:741-52.

33. Kimmel PL, Peterson RA. Depression in patients with end-stage renal disease treated with dialysis: Has the time to treat arrived? Clin J Am Soc Nephrol 2006;1:349-52.

34. Cukor D, Coplan J, Brown C, et al. Depression and anxiety in urban hemodialysis patients. Clin J Am Soc Nephrol 2007;2:484-90.

35. Cukor D, Peterson RA, Cohen SD, Kimmel PL. Depression in end-stage renal disease hemodialysis patients. Nat Clin Pract Nephrol 2006;2:678-87.

36. Kimmel PL, Peterson RA. Depression in end-stage renal disease patients treated with hemodialysis: tools, correlates, outcomes, and needs. Semin Dial 2005;18:917.

37. Kimmel PL, Thamer M, Richard CM, Ray NF. Psychiatric illness in patients with end-stage renal disease. Am J Med 1998; 105:214-21.

38. Kimmel PL, Weihs K, Peterson RA. Survival in hemodialysis patients: the role of depression. J Am Soc Nephrol 1993;4:1227.

39. Beck AT, Ward CH, Mendelson M, et al. An inventory for measuring depression. Arch Gen Psychiatry 1961;4:561-71.

40. Hathaway SR, McKinley JC. Manual for the Minnesota Multiphasic personality inventory. New York: Psychological Corporation; 1943.

41. Hathaway CR, McKinley JC. MMPI test manual. Revised. New York: The Psychological Corporation; 1961. p 22.

42. Kadri ZN, Tye Cy. Role of Minnesota Multiphasic Personality Inventory in the diagnosis of psychiatric conditions. Singapore Med J 1972;13:7-13.

43. Ware JE Jr, Sherbourne CD. The MOS 36item short-form health survey (SF-36). I. Conceptual framework and item selection. Med Care 1992;30:473-83.

44. Spitzer RL, Kroenke K, Williams JB. Validation and utility of a self-report version of PRIME-MD: the PHQ primary care study. Primary Care Evaluation of Mental Disorders. Patient Health Questionnaire. JAMA 1999;282:1737-44.

45. Hamilton M. A rating scale for depression. J Neurol Neurosurg Psychiatry 1960;23:5662.

46. Berrios GE, Bulbena-Villarasa A. The Hamilton Depression Scale and the numerical description of the symptoms of depression. Psychopharmacol Ser 1990;9:80-92.

47. Radloff L. The CES-D Scale: a self-report depression scale for research in the general population. Appl Psychol Measur 1977;1:385-401.

48. Zung W. A self-rating depression scale.
Arch Gen Psychiatry 1965;12:63-70.

49. Sonikian M, Metaxaki P, Papavasileiou D, et al. Effects of interleukin-6 on depression risk in dialysis patients. Am J Nephrol 2010;31:303-8.

50. Giannaki CD, Sakkas GK, Karatzaferi C, et al. Evidence of increased muscle atrophy and impaired quality of life parameters in patients with uremic restless legs syndrome. PLoS One 2011;6:e25180.

51. Lopes AA, Albert JM, Young EW, et al. Screening for depression in hemodialysis patients: associations with diagnosis, treatment, and outcomes in the DOPPS. Kidney Int 2004;66:2047-53.

52. Wuerth D, Finkelstein SH, Ciarcia J, et al. Identification and treatment of depression in a cohort of patients maintained on chronic peritoneal dialysis. Am J Kidney Dis 2001;37:1011-7.

53. Kennedy SH, Craven JL, Roin GM. Major depression in renal dialysis patients - an open trial of antidepressant therapy. J Clin Psychiatry 1989;50:60-3.

54. Lee SK, Lee HS, Lee TB, et al. The effects of antidepressant treatment on serum cytokines and nutritional status in hemodialysis patients. J Korean Med Sci 2004;19:384-9.

55. Koo JR, Yoon JY, Joo MH, et al. Treatment of depression and effect of antidepression treatment on nutritional status in chronic hemodialysis patients. Am J Med Sci 2005;329:1-5.

56. Turk S, Atalay H, Altintepe L, et al. Treatment with antidepressive drugs improved quality of life in chronic hemodialysis patients. Clin Nephrol 2006; 65:113-8.

57. Levy NB, Blumenfield M, Beasley CM Jr, et al. Fluoxetine in depressed patients with renal failure and in depressed patients with normal kidney function. Gen Hosp Psychiatry 1996;18:8-13.

58. Duarte PS, Miyazaki MC, Blay SL, Sesso R. Cognitive-behavioral group therapy is an effective treatment for major depression in hemodialysis patients. Kidney Int 2009;76:414-21.

59. Lii YC, Tsay SL, Wang TJ. Group intervention to improve quality of life in haemodialysis patients. J Clin Nurs 2007; 16:268-75.

60. Rocha Augusto C, Krzesinski JM, Warling $\mathrm{X}$, et al. [The role of psychological interventions in dialysis: an exploratory study]. Nephrol Ther 2011;7:211-8. [Article in French].

61. Jorm AF, Morgan AJ, Hetrick SE. Relaxation for depression. Cochrane Database Syst Rev 2008:CD007142.

62. Tsay SL, Hung LO. Empowerment of patients with end-stage renal disease-a randomized controlled trial. Int $\mathrm{J}$ Nurs 
Stud 2004:41:59-65.

63. Cho YC, Tsay SL. The effect of acupressure with massage on fatigue and depression in patients with end-stage renal disease. $\mathrm{J}$ Nurs Res 2004;12:51-9.

64. Kim KB, Lee MH, Sok SR. [The effect of music therapy on anxiety and depression in patients undergoing hemodialysis]. Taehan Kanho Hakhoe Chi 2006;36:321-9. [Article in Korean]

65. Babyak M, Blumenthal JA, Herman S, et al. Exercise treatment for major depression: maintenance of therapeutic benefit at 10 months. Psychosom Med 2000;62:633-8.

66. Kouidi E, Karagiannis V, Grekas D, et al., Depression, heart rate variability, and exercise training in dialysis patients. Eur J Cardiovasc Prev Rehabil 2010;17:160-7.

67. Jung TD, Park SH. Intradialytic exercise programs for hemodialysis patients. Chonnam Med J 2011;7:61-5.

68. Patel SS, Shah VS, Peterson RA, Kimmel PL. Psychosocial variables, quality of life, and religious beliefs in ESRD patients treated with hemodialysis. Am J Kidney Dis 2002;40:1013-22.

69. Cohen LM, Tessier EG, Germain MJ, Levy NB. Update on psychotropic medication use in renal disease. Psychosomatics 2004;45:34-48.

70. Kalender B, Ozdemir AC, Yalug I,
Dervisoglu E. Antidepressant treatment increases quality of life in patients with chronic renal failure. Ren Fail 2007;29: 817-22.

71. Kimura H, Ozaki N. Diagnosis and treatment of depression in dialysis patients. Ther Apher Dial 2006;10:328-32.

72. Beck AT. Depression: clinical, experimental, and theoretical aspects. New York: Hoeber Medical Division; 1967. p 370.

73. Beck AT, Rush AJ, Shaw BF, Emery G. Cognitive therapy of depression. New York: The Guilford Press; 1979.

74. Leake R, Friend R, Wadhwa N. Improving adjustment to chronic illness through strategic self-presentation: an experimental study on a renal dialysis unit. Health Psychol 1999;1:54-62.

75. Symister P, Friend R. The influence of social support and problematic support on optimism and depression in chronic illness: a prospective study evaluating selfesteem as a mediator. Health Psychol 2003;22:123-9.

76. Krespi MR, Oakley D, Bone M, et al. [The effects of visual imagery on adjustment and quality in life of hemodialysis patients]. Turk Psikiyatri Derg 2009;20:255-68. [Article in Turkish]

77. Lin YJ, Lu KC, Chen CM, Chang CC. The effects of music as therapy on the overall well-being of elderly patients on maintenance hemodialysis. Biol Res Nurs 2012;14:277-85.

78. Anand S, Johansen KL, Grimes B, et al. Physical activity and self-reported symptoms of insomnia, restless legs syndrome, and depression: the comprehensive dialysis study. Hemodial Int 2013;17:50-8.

79. Dunn AL, Trivedi MH, O'Neal HA. Physical activity dose-response effects on outcomes of depression and anxiety. Med Sci Sports Exerc 2001;33:S587-97.

80. Giannaki CD, Sakkas GK, Karatzaferi C, et al. Effect of exercise training and dopamine agonists in patients with uremic restless legs syndrome: a six-month randomized, partially double-blind, placebo-controlled comparative study. BMC Nephrol 2013;14:194.

81. Giannaki CD, Hadjigeorgiou GM, Karatzaferi C, et al. A single-blind randomized controlled trial to evaluate the effect of 6 months of progressive aerobic exercise training in patients with uraemic restless legs syndrome. Nephrol Dial Transplant 2013;28:2834-40. 